\title{
The Regulation of Transmitter Expression in Postembryonic Lineages in the Moth Manduca sexta. I. Transmitter Identification and Developmental Acquisition of Expression
}

\author{
Jane L. Witten ${ }^{a}$ and James W. Truman \\ Department of Zoology, University of Washington, Seattle, Washington 98195
}

The majority of the neurons in the adult nervous system of Manduca sexta are born postembryonically, during larval life. Stereotypic arrays of identifiable neuroblasts generate their clonal families or lineages commencing at the end of the second larval instar through pupal day 2 , when the neuroblasts die (Booker and Truman, 1987a). We have used immunohistochemical techniques to follow the neurochemical differentiation of GABA and a peptide similar to molluscan small cardioactive peptide $B\left(S C P_{B}\right)$ in identified lineages. We report here the distribution and developmental acquisition of the expression of these putative transmitters.

There are 24 postembryonic lineages in the second thoracic ganglion of the larvae (Booker and Truman, 1987a). Immunoreactivity against GABA and $\mathbf{S C P}_{B}$ is seen only in a subset of these 24 clonal families. GABA immunoreactivity is confined to the progeny of the $E, K, M, N, T$, and $X$ neuroblasts and is expressed by most or all of the neurons in these lineages. The $S_{C P}$-like immunoreactivity is found in a subset of the neurons in only two clonal groups, the $K$ and $M$ groups, and is colocalized with GABA. These results show that, though heterogeneity in transmitter type exists (GABA, GABA/SCP ${ }_{B}$ ), members of a given lineage share at least some features (GABA) in common.

The onset of transmitter expression was followed in detail for the $\mathrm{K}$ - and $\mathrm{M}$-lineage neurons. During the larval stages, the postembryonic lineage cells are developmentally arrested in a partially differentiated state (Booker and Truman, 1987a) and do not express transmitter immunoreactivity at this time. Their maturation resumes with the onset of metamorphosis. The cells begin to enlarge during the larval-pupal transformation, and both GABA and the $\mathrm{SCP}_{\mathrm{B}}$-like immunoreactivities begin to appear at $25-30 \%$ of the pupal-adult transition. Neurons that initially express GABA immunoreactivity continue to express It throughout adult development. $\mathrm{SCP}_{\mathrm{B}}$-like expression occurs transiently in the $M$ lineages of the thoracic ganglia (T1-T3) but then remains only in the $M$-lineage neurons in the first abdominal ganglion (A1). In

Received Aug. 31, 1990; revised Jan. 25, 1991; accepted Jan. 31, 1991.

This work was supported by NIH Grants NS-07936 to J.L.W. and NS-13079 to J.W.T. We would like to thank Drs. David Morton, Steve Robinow, Richard Levine, Cindy Rankin, Lynne Oland, and Leslie Tolbert for their critical reading of the manuscript.

Correspondence should be addressed to Jane L. Witten, 611 Gould-Simpson Science Building, Arizona Research Laboratories Division of Neurobiology, University of Arizona, Tucsin, AZ 85721

a Present address: Arizona Research Laboratories Division of Neurobiology University of Arizona, Tucson, AZ 85721 .

Copyright (C) 1991 Society for Neuroscience $0270-6474 / 91 / 111980-10 \$ 03.00 / 0$ contrast, it is stably expressed in all of the $\mathrm{K}$ lineages. These results suggest that both cell lineage and segment-specific factors may be important in establishing transmitter types in the postembryonically generated neurons.

Neurons differ markedly in their morphological and biochemical properties as well as their functions. Studies in insects, nematode, and leech have shown that both cell lineage (Sulston and Horvitz, 1977; Goodman et al., 1979; Taghert and Goodman, 1984; Stuart et al., 1987) and cell-cell interactions (Doe and Goodman, 1985; Doe et al., 1985; Kuwada and Goodman, 1985) are involved in determining features such as transmitter expression and axonal trajectory in the CNS. The actions of glucocorticoids on vertebrate peripheral neurons (Eränko et al., 1972; Thoenen and Otten, 1978; Bohn et al., 1984; Doupe et al., 1985a,b), and 20-hydroxyecdysone on insect motoneurons (Levine and Truman, 1985; Weeks and Truman, 1985; Truman and Reiss, 1988) suggest that circulating factors also may play a role in regulating the expression of particular mature phenotypes.

Invertebrate systems have provided valuable insights into the role of cell lineage in determining transmitter phenotypes because of the ability to identify specific stem cells and to follow their progeny through development. Insects that go through complete metamorphosis provide some unique opportunities in this respect because large numbers of neurons destined for eventual incorporation into the CNS of the adult arc born postembryonically, during larval life. These cells occur in discrete, stereotyped clusters within the $\mathrm{CNS}$, each cluster being the progeny of a single, identified neuronal stem cell or neuroblast (Booker and Truman, 1987a). In contrast to the differentiation of embryonically generated neurons, which progresses continuously, the differentiation of the postembryonically generated neurons is interrupted. Shortly after their birth, the postembryonic cells begin to differentiate and extend a neurite into the neuropil. Their development is arrested at this partially differentiated state until the start of metamorphosis, when the cells resume maturation synchronously, regardless of birth date. These changes are under the control of the steroid hormones that cause metamorphosis (Booker and Truman, 1987b).

Each thoracic ganglion of larvae of the tobacco hornworm, Manduca sexta, contains up to 24 distinct lineages of postmitotic immature neurons. Each lineage is a clone arising from a single neuroblast. The neurons within each lineage typically remain clustered throughout metamorphosis so that in the adult one can examine the properties of all the members of a given clone. This study used immunocytochemical techniques to examine the distribution and developmental acquisition of the 
expression of putative transmitters among the cells of these lineages. We followed the neurochemical differentiation of a known inhibitory transmitter, GABA, and of a putative modulatory transmitter, a peptide similar to molluscan small cardioactive peptide $\mathrm{B}\left(\mathrm{SCP}_{\mathrm{B}}\right)$. The results suggest that the expression of these putative transmitters is restricted to and maintained within particular clonal groups, but that all the neurons within one clonal family need not all express the same transmitter.

\section{Materials and Methods}

\section{Rearing conditions}

Larvae of the tobacco hornworm, Manduca sexta, were reared individually on an artificial diet at $26^{\circ} \mathrm{C}$ under a long day photoperiod of 17 $\mathrm{hr}$ light, $7 \mathrm{hr}$ dark as described by Bell and Joachim (1978). Under these rcaring conditions, it takes approximately $18 \mathrm{~d}$ from hatching to pupal ecdysis, and the adult moth emerges about $20 \mathrm{~d}$ later.

For larval stages and the early portion of adult development, animals were timed relative to discrete developmental events: the ecdysis of each larval stage [third, fourth, and fifth instar day 0 (III +0 , IV +0 , $\mathrm{V}+0$, respectively)], the onset of "wandering" by the fifth stage larva [wandering day $0(\mathrm{~W}+0)$, characterized by cessation of feeding and onset of intense locomotion], and pupal ecdysis $(P+0)$. Besides the number of days past pupal ecdysis, we also used a set of CNS markers associated with ganglion migration and fusion to confirm the early stages of adult development. Pigmentation and cuticular markers (Schwartz and Truman, 1983) were used to stage animals in the last few days of adult development.

Both males and females were used in this study.

\section{Histological methods}

Ganglia were dissected under insect saline (Ephrussi and Beadle, 1936). For paraffin sections, the ganglia were fixed overnight in aqueous Bouin's solution (saturated picric acid, formalin, and glacial acetic acid, 15:5: 1) at room temperature (RT) dehydrated, embedded, sectioned at 10 $\mu \mathrm{m}$ and stained with hematoxylin and eosin.

We corrected our raw counts of lineage cells using the method of Abercrombie (1946) as described in Truman and Booker (1986) to adjust for cells that are counted in more than one adjacent section.

\section{Immunochemical methods}

Different phosphate buffer systems werc used for the 5-bromodeoxyuridine (BUdR), GABA, and $\mathrm{SCP}_{\mathrm{B}}$ antisera to optimize staining. The buffers used were the following: for the anti-BUdR serum, 10-mM phosphate buffer (PB) containing $0.15 \mathrm{M} \mathrm{NaCl}(\mathrm{pH}, 7.4$; buffer $\mathrm{A}$ ), and $0.3 \%$ Triton X-100 (buffer A-X); for the GABA antibody, a 100-mM PB with $0.5 \mathrm{M} \mathrm{NaCl}$ and $0.5 \%$ Triton X-100 (buffer B-X); and for the anti-SCP serum, a $10-\mathrm{mM} P B$ containing $0.15 \mathrm{M} \mathrm{NaCl}$ and $0.1 \%$ Triton X-100 (buffer C-X).

Birth-dating. The incorporation of the thymidine analog 5-bromodeoxyuridine (BUdR) combined with whole-mount immunohistochemistry using a monoclonal antibody against BUdR (Gratzner, 1982) was used to identify neurons undergoing DNA synthesis. Fifth instar larvae were injected with $50 \mu \mathrm{l} / \mathrm{gm}$ body weight of BUdR $(50 \mathrm{mg} / \mathrm{ml})$. Patterns of BUdR incorporation were then assessed either $24 \mathrm{hr}$ later or after metamorphosis in the pharate adult (just prior to adult emergence).

For immunohistochemical analysis, the tissue was fixed in Carnoy's solution (absolute alcohol, chloroform, and acetic acid, 6:3:1) for $2 \mathrm{hr}$ at RT. Preparations were rehydrated and then rinsed in buffer $A-X$. Following incubation in 3\% hydrogen peroxide in buffer A-X for 15 min, the tissue was exposed to $2 \mathrm{~N} \mathrm{HCl}$ in buffer $\mathrm{A}-\mathrm{X}$ for $60 \mathrm{~min}$ to denature the DNA. Following rinsing and blocking of nonspecific staining with a $10 \%$ normal goat serum (NGS) for $2 \mathrm{hr}$, the preparations were incubated in the primary antibody (Becton-Dickinson, Mountain View, CA) at a 1:200 dilution in 1\% NGS in buffer A-X for 2-3 d at $4^{\circ} \mathrm{C}$. Following incubation in the primary antiserum, the tissue was rinsed for $2 \mathrm{hr}$ and then exposed for 1-2 din the cold to the secondary antiserum [biotinylated horse anti-mouse IgG (Vector Labs, Burlingame, CA) at a 1:200 dilution in buffer A-X and 1\% NGS]. Subsequently, it was rinsed and then incubated at RT in a 1:100 dilution of a preformed avidin-biotin-horseradish peroxidase complex [ABC-HRP (Vector Labs)] in buffer A-X for 2 hr. The antibody-antigen complex was visualized using the glucose oxidase $(0.3 \%)$ method of Watson and Burrows (1981) with $0.5 \mathrm{mg} / \mathrm{ml}$ diaminobenzidine (DAB; Sigma) as the substrate. Following this reaction, the tissue was dehydrated, cleared in methyl salicylate, and mounted in Canada balsam.

$G A B A$. For immunohistochemical localization of GABA in both wholemount and paraffin sections, the ganglia were fixed for $4 \mathrm{hr}$ in a mixture of $25 \%$ glutaraldehyde ( 1 part), saturated picric acid ( 3 parts), and acetic acid $\left(1 \%\right.$; GPA; Boer et al., 1979) at $4^{\circ} \mathrm{C}$. They were then dehydrated and stored overnight in $70 \%$ ethanol saturated with lithium carbonate. Tissue for whole-mount immunohistochemistry was rehydrated and stored in PBS until processing. For paraffin sectioning, tissues were dehydrated, embedded in paraffin, sectioned at 8 or $10 \mu \mathrm{m}$, and then processed immunocytochemically.

For immunocytochemical staining for GABA, we utilized a polyclonal antiserum raised in rabbits against GABA conjugated to keyhole limpet hemocyanin (KLH). This antiserum has been well characterized (Hoskins et al., 1986) and was generously provided by Drs. John Hildebrand (University of Arizona) and Timothy Kingan (USDA, Beltsville, MD). To reduce endogenous peroxidase activity and to increase permeability in whole-mount preparations, the ganglia were dehydrated through an alcohol series, placed in methanol containing $3 \%$ hydrogen peroxide for $15 \mathrm{~min}$, rehydrated, incubated for $1 \mathrm{hr}$ at RT in $1 \mathrm{M}$ ethanolamine (Sigma) in a $100 \mathrm{~mm}$ phosphate buffer and then for $1 \mathrm{hr}$ in $1 \mathrm{mg} / \mathrm{ml}$ of collagenase/dispase (Boehringer-Mannheim, Indianapolis, IN) in buffer B-X. Nonspecific binding was blocked with $10 \%$ NGS in buffer B-X for $2 \mathrm{hr}$ at $4^{\circ} \mathrm{C}$. The tissues then were incubated in the anti-GABA serum at a 1:5000 dilution in buffer B-X containing $1 \%$ NGS for $3-4 \mathrm{~d}$ at $4^{\circ} \mathrm{C}$. Subsequently, the tissues were incubated in the secondary antiserum (a biotinylated goat anti-rabbit IgG at 1:200 dilution in buffer B-X and $1 \%$ NGS) followed by incubation in the ABC-HRP complex. The antibody was visualized as described above for the anti-BUdR staining.

For localization of GABA in paraffin sections, the same protocol described above for whole-mount preparations was used with the following modifications: (1) the incubation and rinsing times were shortened (ethanolamine, $30 \mathrm{~min}$; blocking, $60 \mathrm{~min}$; primary antiserum, overnight; secondary antibody, $30 \mathrm{~min}$; ABC-HRP, $60 \mathrm{~min}$; rinses, 15 $30 \mathrm{~min}$ ), (2) no collagenase/dispase was used, and (3) the visualization reaction was done using $0.25 \mathrm{mg} / \mathrm{ml} \mathrm{DAB}$ and $0.01 \%$ hydrogen peroxide instead of the glucose oxidase method.

$S C P_{B}$-like peptide. For localization of the peptide in whole-mount preparations, the ganglia were fixed in $4 \%$ paraformaldehyde in $0.1 \mathrm{M}$ phosphate buffer $(\mathrm{pH}, 7.4)$ for $12-24 \mathrm{hr}$ at $4^{\circ} \mathrm{C}$. Because penetration of the sheath in paraformaldehyde-fixed tissue was not as difficult as after glutaraldehyde fixation, the protocol described for GABA whole-mounts was simplificd as follows: the preparations were rinsed in a $10-\mathrm{mm}$ phosphate-buffered saline $(0.9 \% \mathrm{NaCl})$, dehydrated in a graded alcohol series, exposed to $3 \%$ hydrogen peroxide in methanol $(15 \mathrm{~min})$, and rehydrated. To reduce nonspecific staining, the tissue was incubated in $10 \%$ NGS in buffer C-X for $2 \mathrm{hr}$ at $4^{\circ} \mathrm{C}$ and then incubated for $3-4 \mathrm{~d}$ in the anti-SCP $\mathrm{S}_{\mathrm{B}}$ monoclonal serum provided by Dr. A. O. D. Willows at the University of Washington (Masinovsky et al., 1988) at a 1:20 dilution in buffer C-X with $1 \%$ NGS at $4^{\circ} \mathrm{C}$. Subsequently, the tissue was incubated in the secondary antiserum [biotinylated horse anti-mouse IgG (Vector Labs) 1:200 in buffer C-X and 1\% NGS] for 1-2 d, rinsed again, and incubated in the ABC-HRP for $2 \mathrm{hr}$. After a final rinse, the peroxidase label was visualized as described above.

Colocalization of $G A B A$ and the $S C P_{B}$-like peptide. For colocalization of GABA and the $\mathrm{SCP}_{\mathrm{B}}$-like peptide, the tissue was fixed in GPA and processed for paraffin sectioning. Alternate sections were mounted on separate slides and then processed for immunohistochemistry as previously described except that the dilution of the anti-SCP ${ }_{B}$ serum was reduced to 1:5 and the ABC 'Elite' solution (Vector Labs) was used.

Preabsorption controls. Preabsorption controls for the specificity of the GABA antiserum were performed by incubating the diluted antiserum with $8 \mu \mathrm{g} / \mathrm{ml}$ of GABA-BSA (bovine serum albumin) conjugates overnight prior to immunohistochemistry as described by Hoskins et al. (1986). All specific GABA staining in whole-mounts and sectioned material was blocked by this preabsorption.

Preabsorbing the anti-SCP ${ }_{\mathrm{B}}$ serum with $10^{-4} \mathrm{M} \mathrm{SCP}_{\mathrm{B}}$ (Peninsula, Belmont, CA) as described by Masinovsky et al. (1988) eliminated staining in Manduca sexta. Preabsorption with $10^{-4} \mathrm{M}$ Phe-Met-Arg-Pheamide (FMRFamide; Peninsula) caused a slight reduction in the staining. Lower concentrations of either peptide were ineffective. 

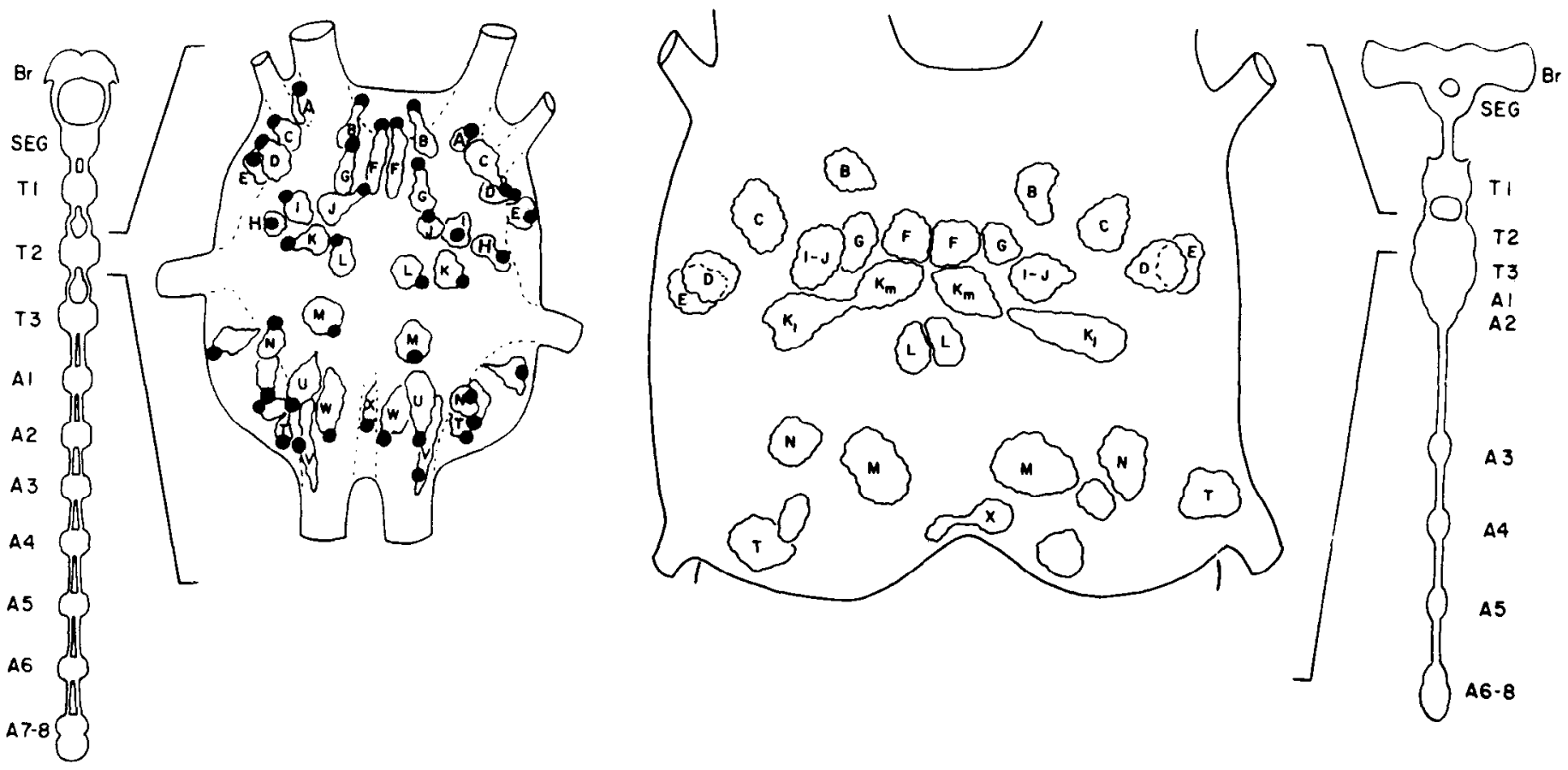

Figure 1. Map of the postembryonic lineages in the larval and adult T2 ganglion. During the transformation to the adult, fusion of the ganglia occurs in the thorax. The pterothoracic ganglion is formed from fusion of T2 and T3 with Al and A2. The larval T2 ganglion contains 47 lineages, 23 paired and one unpaired (Booker and Truman, 1987a). The positions of the neuroblasts (solid circles) and their associated progeny (outlines) are shown on the left. All members of the posterior lateral group of neuroblasts ( $N$ through $T$ ) in the larval ganglion have not been included because they cannot be uniquely identified in different individuals (Booker and Truman, 1987a). Only the $N$ and $T$ neuroblasts with their family of neurons have been labeled in the schematic. The positions of the lineages that we have identified in the adult are shown in the schematic on the right. Lineages in the adult that are unlabeled could not be uniquely identified. Br, brain; SEG, subesophageal ganglion.

\section{Results}

\section{Identification of the postembryonic lineages in the adult thoracic ganglia}

The ganglia of larval Manduca sexta possess a stereotyped set of neuroblasts (Booker and Truman, 1987a; Fig. 1). During larval life, each neuroblast produces up to 120 neurons, which stay as a tightly packed cluster of arrested, partially differentiated neurons and then mature into functional neurons during metamorphosis. The second thoracic ganglion (T2) contains the largest number of neuroblasts: 47 cells, including one unpaired neuroblast and 23 paired neuroblasts. These neuroblasts and their respective lineages can be identified by their positions in the ganglion and by the fact that the progeny of a given neuroblast extend processes that fasciculate together and insert into tracts or commissures that are lineage specific. The various neuroblasts and their neuronal families in $\mathrm{T} 2$ are referred to by letter (A through $\mathrm{X}$ ). Other ganglia contain only a subset of the clonal groups found in T2 (Booker and Truman, 1987a). Lineages are referred to by their letter name (A through $\mathrm{X}$ ), ganglion [thoracic (T) or abdominal (A)], and segment number (1-8) as in Booker and Truman (1987a). For example, the $M$ lineage in the first abdominal segment will be abbreviated as $\mathrm{M}(\mathrm{A} 1)$. During metamorphosis, migration and fusion of specific ganglia occur. In the thorax, ganglia $\mathrm{T} 2, \mathrm{~T} 3, \mathrm{~A} 1$, and $\mathrm{A} 2$ fuse, forming the pterothoracic ganglion, but for simplicity, we will still refer to the individual components of a fused ganglion when identifying lineages.

Serially sectioned ganglia were used to follow the fates of particular clonal populations from the onset of wandering $(W+0)$ through pupal ecdysis $(P+0)$, which occurs $4 \mathrm{~d}$ later, and the first 5-6 d of adult development $(P+1$, etc. $)$. By $P+9$, the ganglia have completed the majority of their growth and have finished fusing, and the neuronal cell bodies have essentially achieved their adult positions. In the larva, the neurons in each lineage group are found in compact clusters, and for the most part, they remain in discrete clusters during metamorphosis. Also, though the position of cells in the ganglia becomes distorted during fusion and growth, the lineages retain their spatial relationships relative to one another. Another criterion for identification of cells in a particular lineage was the various tracts and commissures into which the cells projected. Although the neuropil undergoes considerable distortion during metamorphosis, the spatial relationships of the major tracts are conserved. Most of the rostral and ventral lineages could be followed as discrete entities through metamorphosis. The caudal lineages were more difficult to follow because there are many lineages present in this region of the ganglion. Because they are more closely spaced, we did not try to establish the fates for these lineages except for the obvious $\mathrm{X}$ (median, unpaired) lineage and the $\mathrm{T}$ lineage (designation of the posterior, dorsolateral lineage we followed).

The correspondence between the clusters in the larval and adult stages was established by determining the change in position of each cluster at daily intervals during the transformation. Using this technique we were able to track many of the larval lineages into the adult, where they comprised discrete clusters of small neurons (Fig. 1). Without using this procedure, we would not have been able to identify some of the clusters in the adults. For example, the changes seen in the K clonal family, a lineage unique among the clones followed in that it separates 


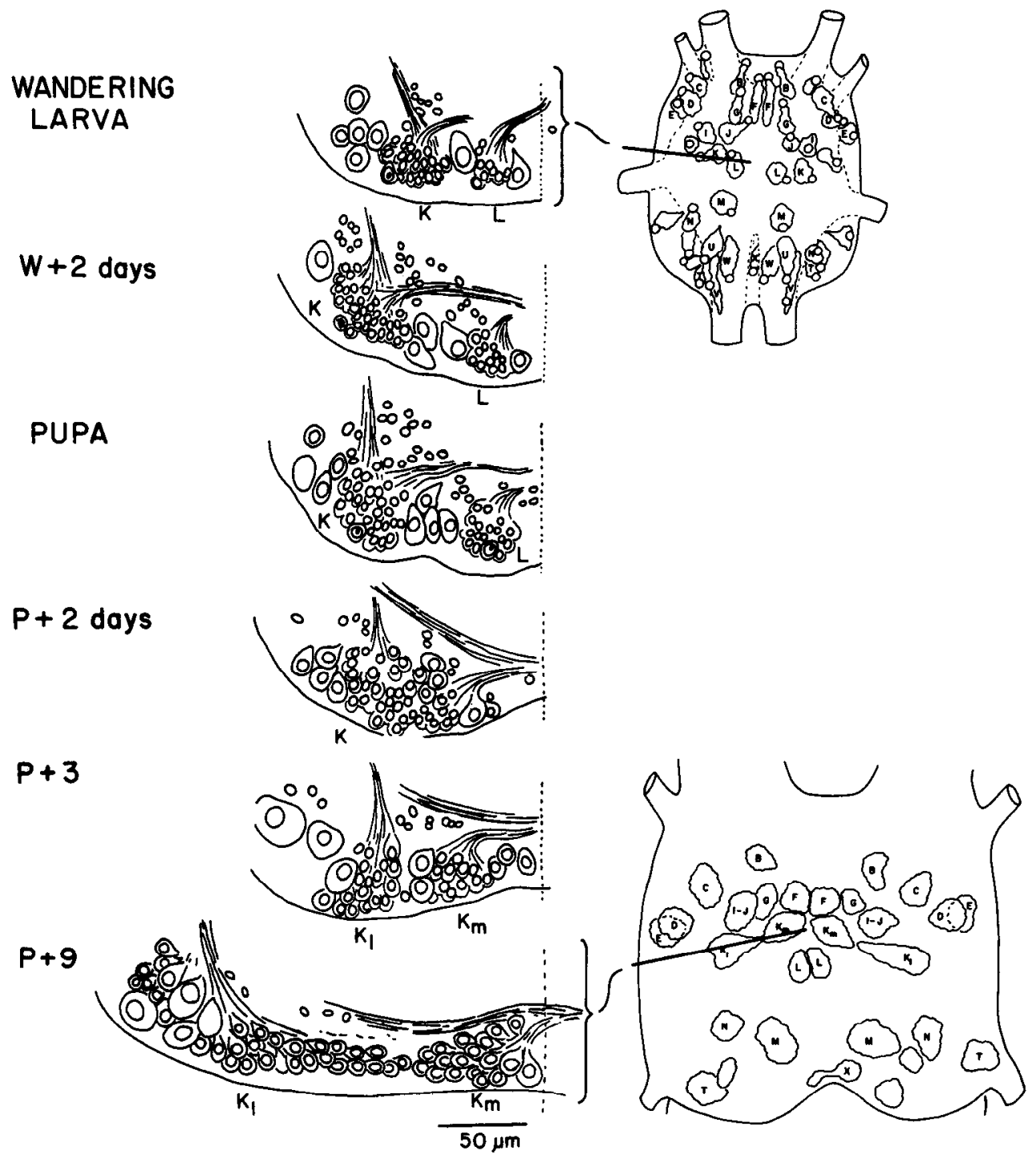

Figure 2. The positional fate of the $\mathbf{K}$ lineage throughout metamorphosis: camera lucida drawings of sections from T2 at the stages indicated. Prior to metamorphosis, the $\mathrm{K}$ lineage is in a lateral position in the ganglion, as is shown in the larval map on the right. At this time, the immature progeny of the $\mathrm{K}$ lineage are already subdivided into two groups based on the trajectories of their primary processes. One set projects contralaterally, inserting into the ventral medial tract, and the other ipsilaterally, into a lateral tract. The two subgroups retain their separate neuropilar insertions and appear to be pulled apart as the ganglion enlarges as metamorphosis progresses. Their final positions are reached by $P+9$, when the group with the contralaterally projecting axons has been moved to a more medial position in the ganglion $\left(K_{m}\right)$ and the ipsilaterally projecting group $\left(K_{l}\right)$ remains lateral. The orientation of the sections is dorsal surface $u p$. into a medial $\left(\mathrm{K}_{m}\right)$ and lateral $\left(\mathrm{K}_{l}\right)$ subgroup during metamorphosis, are illustrated in Figure 2. Prior to the onset of metamorphosis, the developmentally arrested immature K-lineage cells have sent processes into either of two distinct tracts. Some project contralaterally into a ventral medial tract (ventral commissural loop II; Tyrer and Gregory, 1982), and the others inserted ipsilaterally into a lateral tract. When metamorphosis begins and the maturation of the postembryonic cells resumes, the ganglion enlarges due to expansion of the neuropil, and the sites where the cells of the lineage insert into their respective tracts gradually move apart. The cell bodies of the neurons appear to be mechanically separated into the medial and lateral groups during this expansion (Fig. 2). The medial group contains the neurons with contralaterally projecting processes, while the lateral group contains the ipsilaterally projecting axons. The subgroups of the $\mathrm{K}$ lineage are close to their adult positions by $P+6$, and their positions are fully established by $P+9$. In other lineages, such as in the I and $\mathrm{J}$ clonal families, the cell bodies of neurons from adjacent lineages could not be distinguished in the adult stage by position alone.

Immunochemical analysis of sections and whole-mounts of thoracic ganglia from either larvae or adults that had been fed BUdR during larval life showed that the incorporation of BUdR was restricted to discrete clusters of small cells in the larval and adult ganglia (Fig. 3). In the larval ganglia, the labeled cells were confined to the various lineage groups, as had been previously reported by ${ }^{3} \mathrm{H}$-thymidine-incorporation studies (Booker and Truman, 1987a). In the adult, the BUdR again was found almost exclusively in the discrete clusters of small neurons, confirming that these were indeed derived from the larval lineage groups.

The distribution of $G A B A$ and the $S C P_{B}$-like immunoreactivity in postembryonic lineages in the adult thoracic ganglia

Using whole-mount immunohistochemical methods, we mapped the distribution of GABA and the $\mathrm{SCP}_{\mathrm{B}}$-like immunoreactivity to specific postembryonic lineages in the adult ganglia. As seen in Figure 4, GABA immunoreactivity was found in only 6 of the 24 lineages in $T 2$ : three paired ventral lineages, $(K, M, N)$, two paired dorsal lineages $(E, T)$, and the dorsal unpaired lineage (X) $(n=50)$. These six lineages contained GABA-positive cells in all three of the thoracic ganglia. All of the K- and M-lineage neurons $(n=15)$ and the majority of the neurons in the $\mathrm{E}, \mathrm{N}$, 

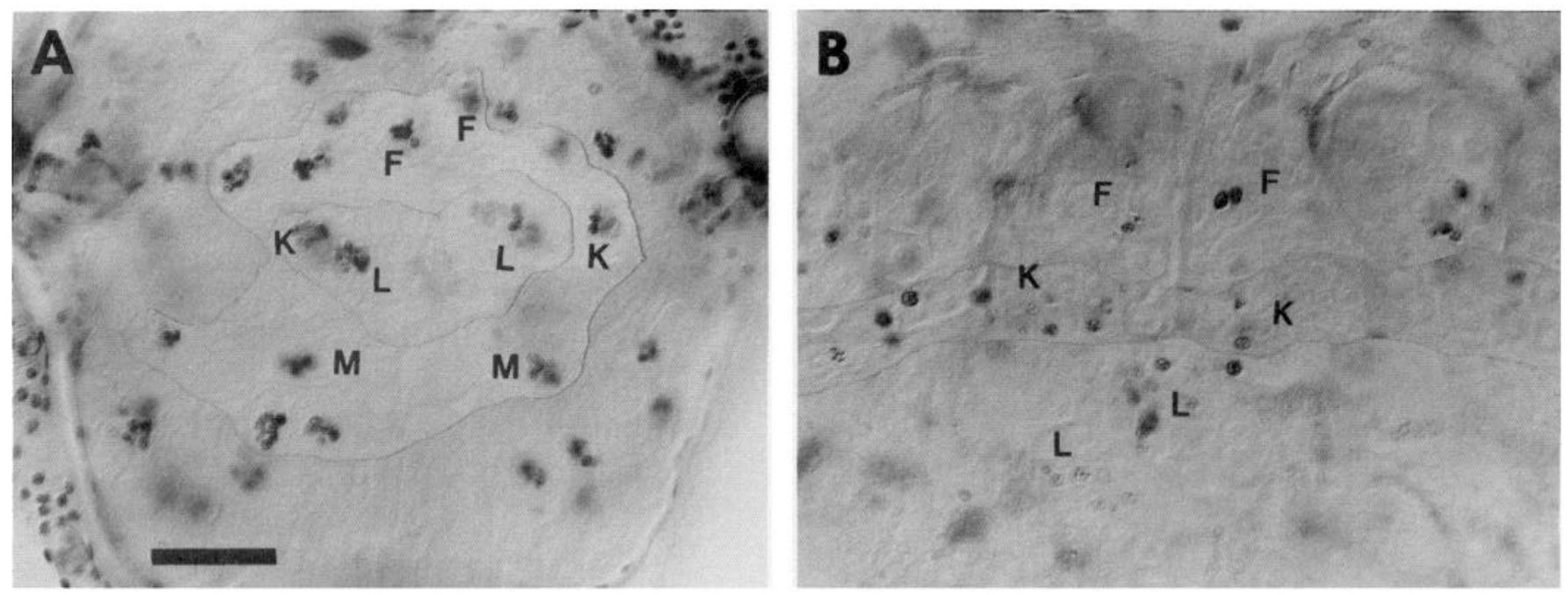

Figure 3. Identification of postembryonic lineages in larval and adult ganglia: photomontages showing the distribution of the neuroblasts and their progeny on the ventral surface of ganglion T2 of a fifth instar larva $(A)$ and pharate adult $(B)$. BUdR $(50 \mathrm{mg} / \mathrm{ml})$ was injected into V+0 larvae, and the incorporation was assessed $24 \mathrm{hr}$ later $(A)$ or after metamorphosis was completed in pharate adults $(B)$. In the larval ganglion $(A)$, the $F$, $K, L$, and $M$ neuroblasts and their progeny are identified. Labeling is also seen in proliferating non-neuronal tissue such as the tracheal cells (left lower edge) and glial cells (right upper corner). During metamorphosis, the neuroblasts die. In the adult (B), the BUdR labeling is found only in clusters of small neurons, confirming that they were derived from the larval clonal groups. The labeled neurons of the $F, K$, and $L$ lineages are indicated. Scale bar, $50 \mu \mathrm{m}$.

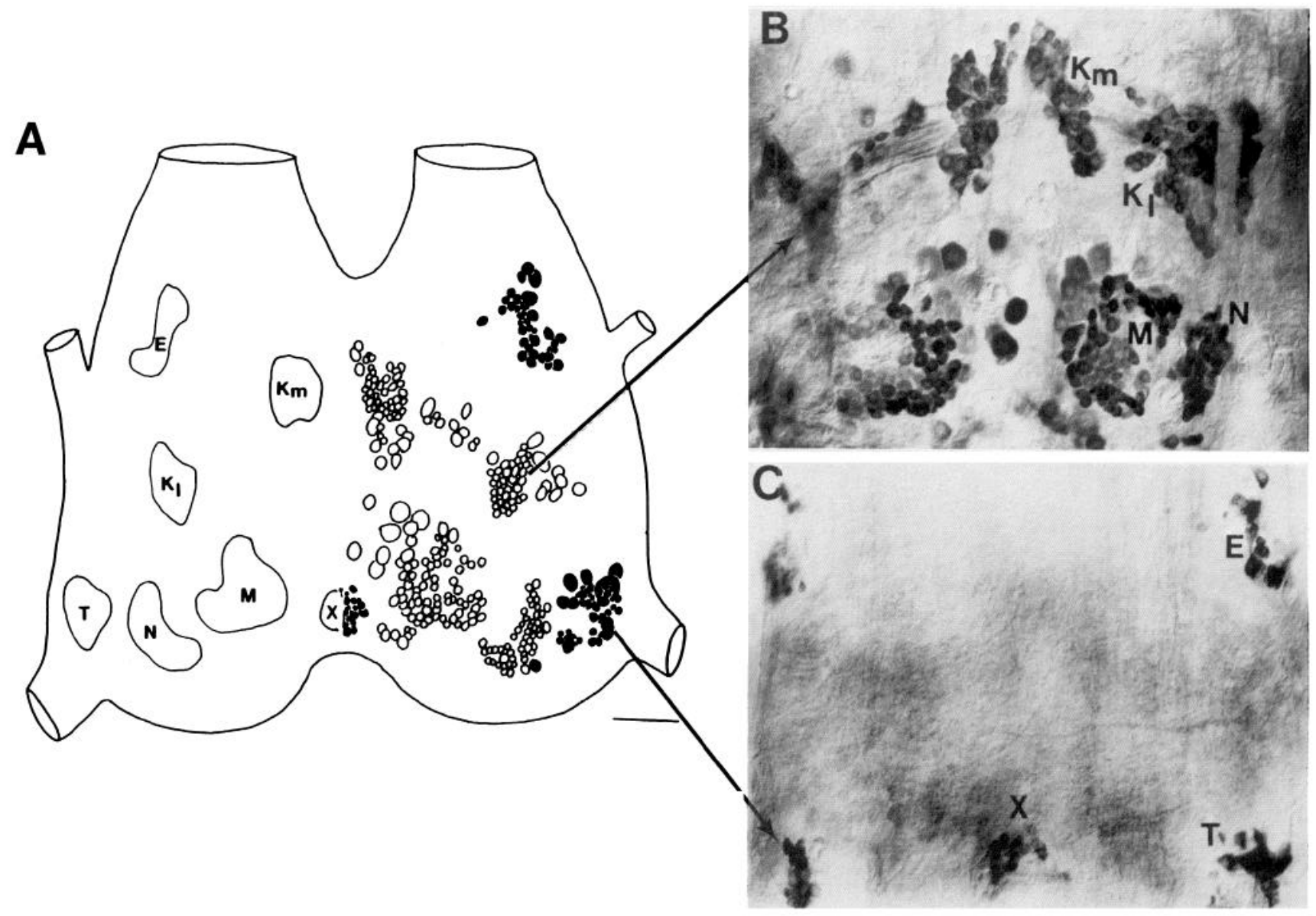

Figure 4. Distribution of the six GABA immunoreactive lineages in ganglion $\mathrm{T} 2$. A, Camera lucida drawing shows the positions of the lineage identification of GABA-immunopositive neurons. There are three ventral paired lineages, $K, M$, and $N$ (open circles), two dorsal paired lineages, $E$ and $T$, and one dorsal unpaired lineages, $X$ (solid circles). To the right are photographs of whole-mount preparations of a T2 stained with the GABA antiserum. The photographs show the three paired ventral lineages, $K$ (subgroups $K_{m}$ and $\left.K_{l}\right), M$, and $N(B)$, and the two paired $(E$, $T$ ), and one unpaired $(X)$ dorsal lineages $(C)$. Scale bar $(B, C), 100 \mu \mathrm{m}$. 


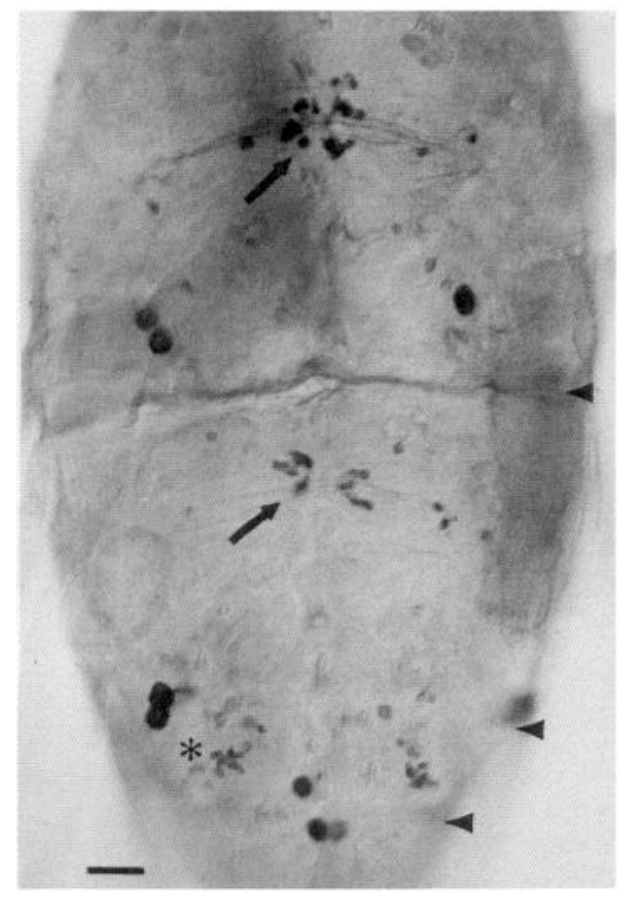

Figure 5. Distribution of the $\mathrm{SCP}_{\mathrm{B}}$-like-immunoreactive lineages in the fused pterothoracic ganglion: photograph of a whole-mount preparation stained with the $\mathrm{SCP}_{\mathrm{B}}$ antiserum showing the $\mathrm{K}_{m}$ neurons in T2 and T3 with their contralaterally projecting axons (arrows) and the M(A1)- (asterisk) immunoreactive neurons. Arrowheads point to the boundaries between $\mathrm{T} 2$ and $\mathrm{T} 3, \mathrm{~T} 3$ and $\mathrm{A} 1$, and $\mathrm{A} 1$ and $\mathrm{A} 2$. The large immunoreactive neurons are thoracic neurosecretory cells. Anterior is to the top. Scale bar, $100 \mu \mathrm{m}$.

$\mathrm{T}$, and $\mathrm{X}$ thoracic lineages $(n=5)$ expressed immunoreactivity to GABA. Abdominal ganglia $\mathrm{A} 1$ and $\mathrm{A} 2$ do not have lineages $\mathrm{E}, \mathrm{K}, \mathrm{X}$, and T, but only M and N (Booker and Truman, 1987a), and both of the latter produced GABA-positive cells $(n=50)$. No additional lineages containing GABA-positive cells were seen in the abdominal ganglia.

Each of the six postembryonic lineages that contained small GABA-immunoreactive neurons $(8-10 \mu \mathrm{m})$ typically was found adjacent to a group of about 15-25 larger (15-20 $\mu \mathrm{m})$ GABAergic neurons (Fig. 4). These groups of large cells were also present in the larval ganglion, but never incorporated BUdR when it was fed to the caterpillars. These observations suggest that these larger GABA-positive cells were born during the embryonic stage of neurogenesis.

Two ventral paired lineages, $\mathrm{K}$ and $\mathrm{M}$, also contained cells immunoreactive to the antiserum against $\mathrm{SCP}_{\mathrm{B}}$ (Fig. 5). The K lineage occurs only in thoracic segments, and each lineage contained a subset of cells (an average of 14) that expressed $\mathrm{SCP}_{\mathrm{B}}$-like immunoreactivity $(n=100)$. These cells all had contralaterally projecting axons and were in the $\mathrm{K}_{m}$ subgroup. Occasionally, we found a few of these cells in an ectopic location among the $\mathrm{K}_{l}$ subgroup despite the fact that they possessed a contralaterally projecting axon. We assume that this occurs due to some $\mathbf{K}_{m}$ cells becoming tangled and moving passively with the other subgroup as the ganglion expands and the groups separate.

In contrast to the expression of the $\mathrm{SCP}_{\mathrm{B}}$-like immunoreactivity in the $\mathrm{K}$ lineage, its expression in the M-lineage neurons was segment specific. The $\mathrm{M}$ lineage is present in all of the

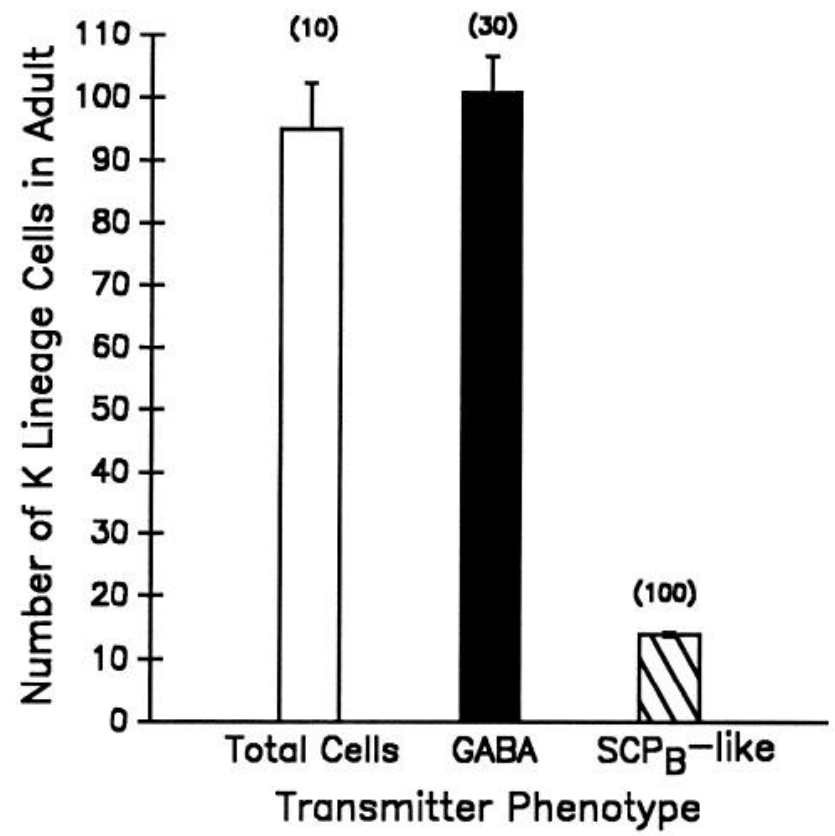

Figure 6. Distribution of the total (open column), GABA- (solid col$u m n$ ), and $\mathrm{SCP}_{\mathrm{B}}$-like (hatched column) immunoreactive neurons in the adult $\mathrm{K}$ lineage. There are approximately 100 neurons in the $\mathrm{K}$ lineage, and all are GABA immunoreactive. A subset of only 14 cells, however, expresses the $\mathrm{SCP}_{\mathrm{B}}$-like phenotype. Values are for means and SEM; number of preparations examined are in parentheses.

thoracic and abdominal ganglia, but the peptide immunoreactivity was confined to the $\mathrm{A} 1$ lineage in the adult (Fig. $5 ; n=$ 53). As will be described below, the thoracic $M$ lineages $[M(T)]$ show a transient expression of this immunoreactivity during the middle portion of adult development, but this expression disappears by the time of adult emergence.

\section{The distribution of putative transmitters within the $K$ lineage}

The $\mathrm{K}$ neuroblast generates approximately 100 cells during larval life, and essentially all survive to become mature neurons in the adult. In T2 and T3, as indicated above, the progeny separate into two groups $\left(\mathrm{K}_{m}\right.$ and $\left.\mathrm{K}_{l}\right)$ containing about 50 cells each. Counts of GABA-positive cells in $\mathrm{K}_{m}$ and $\mathrm{K}_{l}$ totaled about 100 cells (Fig. 6; $n=30$ ). Moreover, in sectioned material all neurons that we would ascribe to the $\mathrm{K}$ lineage were also GABA immunoreactive, suggesting that all the progeny of the $\mathrm{K}$ neuroblast express GABA immunoreactivity. In addition, 14 cells in the $\mathrm{K}_{m}$ subgroup expressed the $\mathrm{SCP}_{\mathrm{B}}$-like phenotype (Fig. 6; $n=100$ ). Thus, all the cells in the $\mathrm{K}$ lineage appear to be GABA positive, and of these, our observations suggest that 14 must also contain the $\mathrm{SCP}_{\mathrm{B}}$-like peptide.

To test whether GABA and the peptide immunoreactivities were colocalized, alternate sections of ganglion $\mathrm{T} 2$ were reacted with the GABA and $\mathrm{SCP}_{\mathrm{B}}$ antisera (Fig. 7; $n=5$ ). All of the cells that stained for the $\mathrm{SCP}_{\mathrm{B}}$-like immunoreactivity also proved to be GABA positive. Thus, the peptide and GABA immunoreactivities are indeed colocalized in the same cells in the $\mathrm{K}_{m}$ sublineage.

\section{Developmental acquisition and expression of the putative transmitter phenotypes in the postembryonic lineages}

The neurochemical differentiation of the GABA and $\mathrm{SCP}_{\mathrm{B}}$-like phenotypes was followed from $\mathrm{V}+\mathrm{O}$ through metamorphosis. 

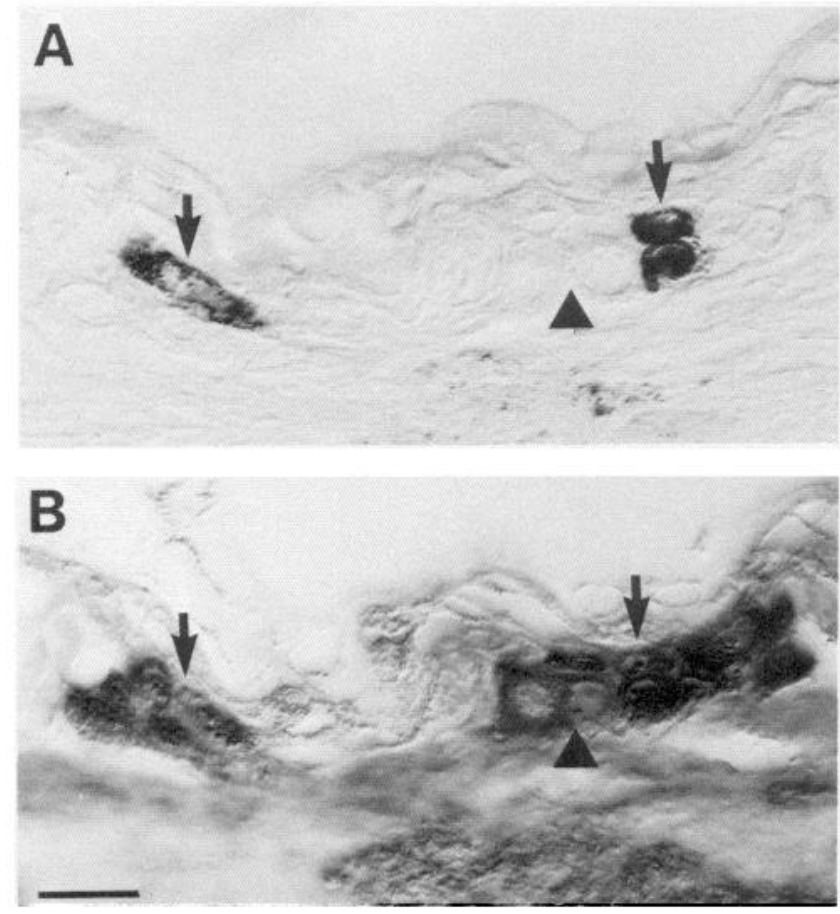

Figure 7. Colocalization of $\mathrm{GABA}$ and the $\mathrm{SCP}_{\mathrm{B}}$-like phenotypes in $\mathrm{K}$-lineage neurons. Alternate sections were stained with the anti-SCP serum $(A)$ and the GABA antisera $(B)$. All the $\mathrm{SCP}_{\mathrm{B}}$-like immunoreactivity is colocalized with GABA (arrows). Cells that are GABA immunoreactive but do not express the peptide are indicated by the arrowheads. Scale bar, $20 \mu \mathrm{m}$.

Development of the postembryonic neurons is arrested soon after their birth during larval life. Accordingly, none of these cells in the larva showed immunoreactivity to either putative transmitter (Figs. 8, 9). Their maturation resumes at wandering, when the steroid hormones, the ecdysteroids, act in the absence of juvenile hormone to promote soma enlargement (Booker and Truman, 1987a,b). As seen in Figure 9, however, expression of the putative transmitter phenotypes was not detected immu-
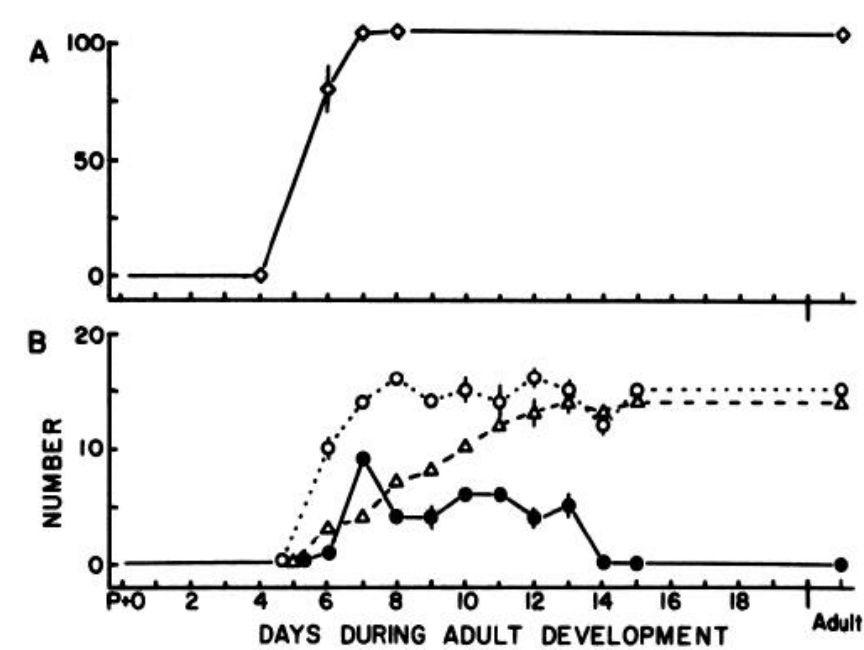

Figure 9. Developmental timetable of the onset of expression of GABA $[$ top, $\mathrm{K}$ lineage $(\diamond)]$ and the $\mathrm{SCP}_{\mathrm{B}}$-like (bottom; $\mathrm{K}[\Delta], \mathrm{M}(\mathrm{A} 1)[\mathrm{O}], \mathrm{M}(\mathrm{T})$ [@] lineages) immunoreactivities in the postembryonic lineages. Transmitter immunoreactivities are not present in the developmentally arrested neurons in larvae. Immunoreactivity to the putative transmitters begins after metamorphosis, when the immature neurons have resumed their maturation. The immunoreactivity to both GABA and the $\mathrm{SCP}_{\mathrm{B}^{-}}$ like peptide first appears early in adult development at about $\mathrm{P}+5-6$ in all lineages. Once the expression begins, it is continuous throughout adult development in all lineages, except for the transient $\mathrm{SCP}_{\mathrm{B}}$-like expression in $\mathrm{M}(\mathrm{T})$-lineage neurons.

nochemically until about $9 \mathrm{~d}$ later, at day $\mathrm{P}+6$ of adult development. Also, transmitter expression is not seen in these cells in diapausing pupae. Animals in diapause are developmentally arrested at approximately day $\mathrm{P}+2$ of adult development, which is prior to the large rise in steroid titer that causes adult development. Thus, transmitter expression is not linked temporally to the hormonal cues that cause the larval-pupal transformation, but rather to those that promote adult differentiation.

The time course of expression of the immunoreactivity to both putative transmitters was examined. We followed the $\mathrm{K}$
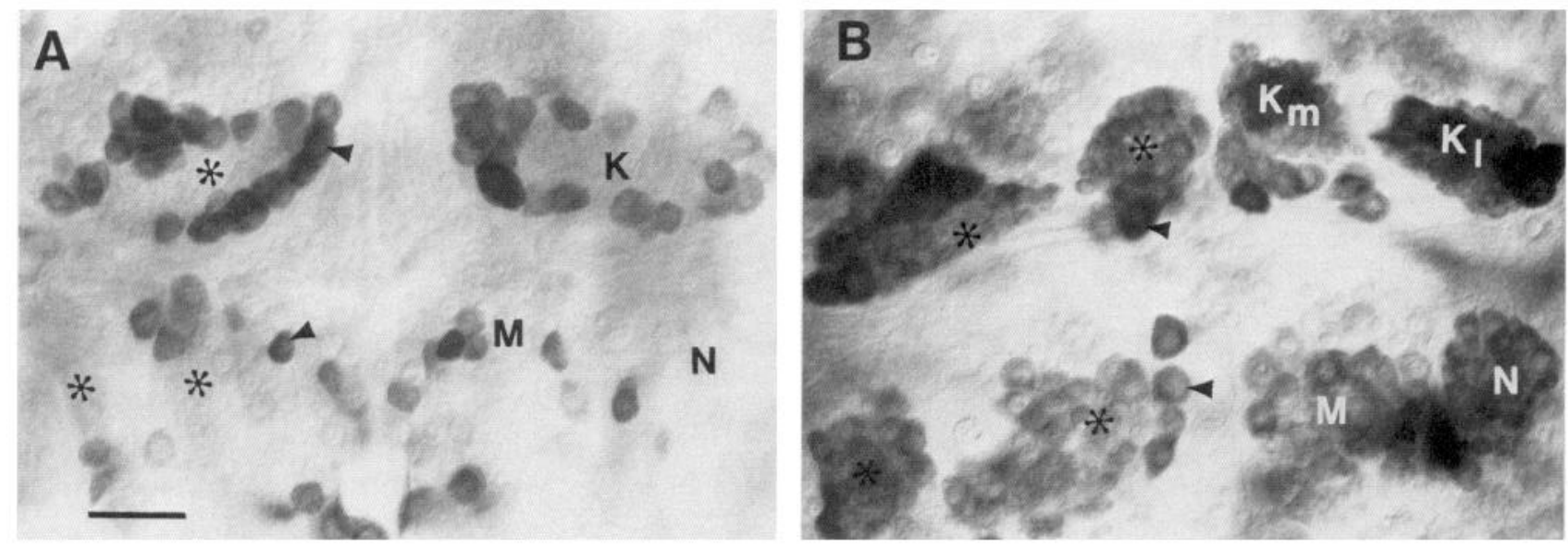

Figure 8. Whole-mount preparations showing the developmental acquisition of the GABAergic phenotype in the $K-, M-$, and $N$-lineage neurons. $A$, Prior to the onset of metamorphosis in a V +3 larva, only the embryonic neurons express GABA immunoreactivity (arrowheads). The smaller, developmentally arrested postembryonic K-lineage neurons (asterisks) have not yet resumed maturation and do not express any immunoreactivity to GABA in the larval stages. $B$, In a P+9 developing adult, the postembryonic neurons in the $K_{m}$ and $K_{l}$ subgroups and the $M$ - and $N$-lineages are still tightly clustered and are expressing GABA immunoreactivity. Anterior is $u p$; ventral surface is shown. Scale bar, $100 \mu \mathrm{m}$. 
and $M$ lineages in detail because they contained both GABAand GABA + SCP ${ }_{\mathrm{B}}$-like-immunoreactive neurons. Faint GABA staining first appeared in the progeny of the $\mathrm{K}$ neuroblast at about days $P+5-6$ of adult development (Fig. 9). Staining intensified over the next $3 \mathrm{~d}$, and by $P+12$, it was similar to that seen in the adult. This pattern of onset of expression was the same in all GABAergic lineages.

Similarly, immunoreactivity against the $\mathrm{SCP}_{\mathrm{B}}$-like peptide also was first detected in the $K$ lineage at $P+5-6$ (Fig. 9) when three cells became immunopositive. As development progressed, more cells began to express the peptide so that by $\mathrm{P}+12$ all $14 \mathrm{~K}_{m}$ cells were immunostaining. At $\mathrm{P}+6$, the immunoreactivity was detected only in the somata and proximal regions of the processes, but by $P+9$ it was distributed throughout the cell. The intensity of the immunoreactivity in the somata and processes increased throughout adult development, achieving the adult pattern by $\mathrm{P}+15$.

$\mathrm{SCP}_{\mathrm{B}}$-like immunoreactivity in the $\mathrm{M}(\mathrm{A} 1)$ lineage was first seen at $P+5-6$ in 10 cells (Fig. 9). Through the next $2 \mathrm{~d}$, the intensity of the staining increased, and the number of positive cells reached the adult level of 15 . We were not able to follow the development of immunoreactivity in the processes of these cells. Interestingly, the $\mathrm{M}(\mathrm{I})$ lineages also showed transient immunoreactivity from $\mathrm{P}+6$ through $\mathrm{P}+13$ (Fig. 9). Staining was seen in the somata of up to eight cells in the thoracic lineages, in the form of a small number of densely staining granules found in the perikaryon. This level of staining was similar to that seen at the onset of expression of the peptide in the $\mathrm{K}_{m}$ sublineage cells. Unlike the latter, however, the $\mathrm{M}(\mathrm{T})$ lineage staining remained at this low level until $P+13$, when the immunoreactivity disappeared.

\section{Discussion}

Over $75 \%$ of the thoracic CNS of the adult moth is derived from neurons born during postembryonic life. These adult-specific cells arise in discrete clusters, each associated with a single neuroblast (Booker and Truman, 1987a). Following their birth, the new neurons arrest their development, and their maturation is delayed until the start of metamorphosis.

We have used serial sectioning combined with BUdR and transmitter immunocytochemistry to follow the positional fates of some of the thoracic lineages throughout metamorphosis. Based on positions of cell clusters and trajectories of primary neurites in the adult ganglia, we could identify more than half of the 24 distinct lineages found in a thoracic ganglion. The more posterior and lateral lineages are compressed during the transformation to the adult, and it was not possible to sort out the individual lineages based on position alone.

Cells that expressed the two putative transmitters, GABA and the $\mathrm{SCP}_{\mathrm{B}}$-like peptide, were not distributed throughout all 24 lineages, but rather were highly restricted. The expression of the putative transmitter GABA is confined to only six lineages $(E$, $K, M, N, T, X$ ), and the majority or all the neurons in each lineage are GABA immunoreactive. GABA is known to be an inhibitory transmitter in locust motoneurons (Emson et al., 1974). It is found in central neurons in locust (Kerkut et al., 1969; Watson, 1986), honeybee (Bicker et al., 1985), cockroach (Baxter and Torralba, 1975), and Drosophila (Chude et al., 1979). In Manduca sexta, it is produced in the CNS (Maxwell et al., 1978; Kingan and Hildebrand, 1985) and has been immunochemically localized to neurons in the brain and subesophageal ganglion (Hoskins et al., 1986; Homberg et al., 1987), where it functions as an inhibitory transmitter for some of the antennal lobe local interneurons (Hoskins et al., 1986). Accordingly, the presence of GABA immunoreactivity in the postembryonic lineages in the thorax suggests that these cells also may function as inhibitory interneurons for certain adult-specific behaviors.

The $\mathrm{SCP}_{\mathrm{B}}$-like immunoreactivity is confined to only two lineages, $K$ and $M$. At this time, we do not know the nature of the peptide that is being recognized by the antibody. Recently, a member of the FMRFamide family has been sequenced in Manduca sexta (Kingan et al., 1990). Antisera raised against synthetic FMRFamide (generously provided by Drs. R. Calabrese, Emory University, and E. Marder, Brandeis University) also stained the $\mathrm{K}$ - and $\mathrm{M}$-lineage neurons. Because the $\mathrm{SCP}_{\mathrm{B}}$ antiserum cross-reacts with FMRFamide (Masinovsky et al., 1988), it is likely that it is recognizing a member of the Manduca sexta FMRFamide peptide family.

Unlike the GABA staining, which showed no segment-specific pattern, the $\mathrm{SCP}_{\mathrm{B}}$-like immunoreactivity showed interesting variability. It was expressed in a subset of the $\mathrm{K}$-lineage neurons in all segments where the $\mathrm{K}$ lineage occurs (T 1-T3). In contrast, stable expression was found in the $M$ lineage only in one segment (A1) despite the fact that this lineage occurs in all ganglia from $\mathrm{T} 1$ to $\mathrm{A} 8$. Interestingly, $\mathrm{SCP}_{\mathrm{B}}$-like immunoreactivity did occur transiently in this lineage in other ganglia (T1-T3). It first appeared in ganglia $\mathrm{T} 1-\mathrm{A} 1$ on day $\mathrm{P}+5$, but by $\mathrm{P}+13$ this expression had disappeared from the thoracic components, leaving immunoreactivity only in A1. This loss of staining could result from cessation of peptide synthesis, or it could mean that subsequent processing might occur differently in thoracic cells as compared to their abdominal counterparts. A last possibility is that the thoracic cells die, but because the disappearance of the staining occurs more than $10 \mathrm{~d}$ after the period of cell death in the ganglia (Booker and Truman, 1987b), this alternative appears unlikely. Thus, the $\mathrm{SCP}_{\mathrm{B}}$-like neurons present in the adult arise from different neuroblasts in different segments.

The larva has six clusters of larger GABA-immunoreactive neurons that are associated with the six postembryonic lineages that also give rise to GABA-positive cells. In many cases, the initial neurite trajectories of the embryonically derived cells are in the same tracts as seen for the postembryonic lineages. Comparative studies on the Tsetse fly, Glossina palidipes (J. W. Truman, unpublished observations), and the fruitfly, Drosophila melanogaster (Prokop and Technau, 1991), show that the postembryonic neuroblasts are the same cells that earlier had generated the embryonic lineages. Based on these observations, we think it likely that these larger neurons represent the embryonic progeny of the neuroblasts that later produced the various postembryonic lineages. If so, then transmitter phenotype is a highly conserved feature of the embryonic and postembryonic progeny of these neuroblasts.

The conservation of transmitter phenotype within the lineages we examined was an unexpected result of this study. In all six lineages that expressed GABA immunoreactivity, all $(\mathrm{K}, \mathrm{M})$ or almost all $(E, N, T, X)$ the cells in each lineage were GABA positive. The cells in each lineage were not homogeneous, however, because a subset of the cells in both the $M$ and $K$ lineages also expressed an $\mathrm{SCP}_{\mathrm{B}}$-like peptide. That a lineage can be heterogeneous in terms of transmitter phenotype is consistent with the findings of Taghert and Goodman (1984) showing that locust neuroblast $7-3$ produces both $5-\mathrm{HT}-$ and non-5-HT-positive cells among its early progeny.

The postembryonic progeny of the median unpaired neuro- 
blast (X) of the moth are GABAergic. In the metathoracic ganglion (T3) of the locust embryo, the dorsal unpaired median neuroblast produces a lineage of approximately 80 neurons. The identifiable, large, and first-born progeny of the locust ncuroblasts stain with neutral red and have been shown to contain octopamine (Goodman et al., 1979). If the unpaired median neuroblasts of the moth and locust were homologous, and if we assume that the postembryonic lineage represents the later-born members of the moth's lineage, then one might expect that the smallest, later-born progeny of the locust neuroblast may also be GABA immunoreactive. Staining of the locust metathoracic ganglia with the anti-GABA serum reveals an unpaired cluster of small cells on the dorsal surface adjacent to each set of large identifiable octopaminergic cells (Thompson and Siegler, 1989; Witten and Truman, 1989). Due to their location and number, it is likely that these small GABAergic neurons are the laterborn progeny of the median neuroblast. It is likely, therefore, that this median neuroblast also produces progeny with two different putative transmitter phenotypes, octopamine and GABA. Thus, there is heterogeneity in transmitter expression, especially in large lineages, but the tendency is for the progeny of a given neuroblast to share at least some properties in common.

In the locust T3 ganglion, Burrows and Siegler (1982) and Siegler and Burrows (1984) have demonstrated that a midline ventral group of neurons function as local inhibitory interneurons integrating leg sensory information. Watson (1986) has shown that these neurons are immunoreactive to GABA. This functionally related group of neurons is in the same position in the locust $T 3$ ganglion as are the GABA-immunoreactive K-lineage cells in the moth thoracic ganglia. Furthermore, the primary neurites from the locust ventral midline group and the moth's $\mathrm{K}$ lineage insert into homologous tracts (ventral commissure II). These similarities suggest that these lineages may be homologous. At this time we do not know the function of the $\mathrm{K}$-lincage ncurons in moths, but these similarities raise the possibility that some lineages may comprise a functionally related group and be a means of organizing the developing CNS into discrete behavioral units.

\section{References}

Abercrombie M (1946) Estimation of nuclear population from microtome sections. Anat Rec 94:239-247.

Baxter CF, Torralba GR (1975) $\gamma$-Amino-butyric acid and glutamate decarboxylase (L-glutamate 1-carboxylyase E.C. 4.1.15) in the ncrvous system of the cockroach, Periplaneta americana. I. Regional distribution and properties of the enzyme. Brain Res 84:383-397.

Bell RA, Joachim FG (1978) Techniques for rearing laboratory colonies of tobacco hornworms and pink bollworms. Ann Entomol Soc Am 69:365-373.

Bicker G, Schafer S, Kingan TG (1985) Mushroom body feedback interneurons in the honeybee show GABA-like immunoreactivity. Brain Res 360:394-397.

Boer HH, Schot LPC, Roubos EW, Maat A, Lodder JC, Reichelt D (1979) ACTH-like immunoreactivity in two electronically coupled giant neurons in the pond snail Lymnaea stagnalis. Cell Tissue Res 202:231-240.

Bohn MC, Bloom E, Goldstein M, Black IB (1984) Glucocorticoid regulation of phenylethanolamine- $N$-methyltransferase (PNMT) in organ culture of superior cervical ganglia. Dev Biol 105:130-136.

Booker R, Truman JW (1987a) Postembryonic neurogenesis in the CNS of the tobacco hornworm, Manduca sexta. I. Neuroblast arrays and the fate of their progeny during metamorphosis. J Comp Neurol 255:548-559.

Booker R, Truman JW (1987b) Postembryonic neurogenesis in the
CNS of the tobacco hornworm, Manduca sexta. II. Hormonal control of imaginal nest cell degeneration and differentiation during metamorphosis. J Neurosci 7:4107-4114.

Burrows M, Siegler MVS (1982) Spiking local interneurons mediate local reflexes. Science 217:650-652.

Chude O, Roberts E, Wu J-Y (1979) Partial purification of Drosophila glutamate decarboxylase. J Neurochem 32:1409-1415.

Doe CQ, Goodman CS (1985) Neurogenesis in grasshopper and fushi tarazu Drosophila embryos. Cold Spring Harbor Symp Quant Biol 50:891-903.

Doe CQ, Kuwada JY, Goodman CS (1985) From epithelium to neuroblasts to neurons: the role of cell interactions and cell lineage during insect neurogenesis. Philos Trans R Soc Lond [Biol] 312:67-81.

Doupe AJ, Landis SC, Patterson PH (1985a) Environmental influences on the development of neural crest derivatives: glucocorticoids, growth factors and chromaffin cell plasticity. J Neurosci 5:2119-2142.

Doupe AJ, Patterson PH, Landis SC (1985b) Small intensely fluorescent cells in culture: role of glucocorticoids and growth factors in their development and interconversions with other neural crest derivatives. J Neurosci 5:2143-2160.

Emson PC, Burrows M, Fonnum F (1974) Levels of glutamate decarboxylase, choline acetyltransferase and acetylcholinesterase in identified motoneurons of the locust. J Neurobiol 5:33-42.

Ephrussi B, Beadle GW (1936) A technique of transplantation for Drosophila. Am Nat 70:218-225.

Eränko O, Eränko L, Hill CE, Burnstock G (1972) Hydrocortisone induced increase in the number of small intensely fluorescent cclls and their histochemically demonstrable catecholamine content in cultures of sympathetic ganglia of the newborn rat. Histochem J 4:4958.

Goodman CS, O'Shea M, McCaman R, Spitzer NC (1979) Embryonic development of identified neurons: temporal pattern of morphological and biochemical differentiation. Science 204:1219-1222.

Gratzner HG (1982) Monoclonal antibody to 5-bromo- and 5-iododeoxyuridine: a new reagent for detection of DNA replication. Science 218:474-475.

Homberg U, Kingan T, Hildebrand JG (1987) Immunocytochemistry of GABA in the brain and suboesophageal ganglion of Manduca sexta. Cell Tissue Res 248:1-24.

Hoskins SG, Homberg U, Kingan TG, Christensen TA, Hildebrand JG (1986) Immunocytochemistry of GABA in the antennal lobes of the sphinx moth Manduca sexta. Cell Tissue Res 244:243-252.

Kerkut GA, Pitman RM, Walker RJ (1969) Iontophoretic application of acetylcholine and GABA onto insect central neurones. Comp Biochem Physiol 31:611-633.

Kingan TG, Hildebrand JG (1985) $\gamma$-Aminobutyric acid in the central nervous system of metamorphosing and mature Manduca sexta. Insect Biochem 15:667-675.

Kingan TG, Teplow DB, Phillips JM, Riehm JP, Rao KR, Hildebrand JG, Homberg U, Kammer AE, Jardine I, Griffin PR, Hunt DF (1990) A new peptide in the FMRFamide family isolated from the CNS of the hawkmoth, Manduca sexta. Peptides 11:849-856.

Kuwada JY, Goodman CS (1985) Neuronal determination during embryonic development of the grasshopper nervous system. Dev Biol 110:114-126.

Levine RB, Truman JW (1985) Dendritic reorganization of abdominal motoneurons during metamorphosis of the moth, Manduca sexta. J Neurosci 5:2424-2431.

Masinovsky B, Kempf SC, Callaway JC, Willows AOD (1988) Monoclonal antibodies to the molluscan small cardioactive peptide $\mathrm{SCP}_{\mathrm{B}}$ : immunolabelling of neurons in diverse invertebrates. J Comp Neurol 273:500-512.

Maxwell GD, Tait JF, Hildebrand JG (1978) Regional synthesis of neurotransmitter candidates in the CNS of the moth, Manduca sexta. Comp Biochem Physiol 61C:109-119.

Prokop A, Technau GM (1991) The origin of postembryonic neuroblasts in the ventral nerve cord of Drosophila melanogaster. Development 111:79-88.

Schwartz LM, Truman JW (1983) Hormonal control of rates of metamorphic development in the tobacco hornworm, Manduca sexta. Dev Biol 99:103-114.

Siegler MVS, Burrows M (1984) The morphology of two groups of spiking local interneurons in the metathoracic ganglion of the locust. J Comp Neurol 224:463-482.

Stuart DK, Blair SS, Weisblat DA (1987) Cell lineage, cell death, and 
the developmental origin of identified serotonin- and dopamine-containing neurons in the leech. J Neurosci 7:1107-1122.

Sulston JE, Horvitz HR (1977) Postembryonic cell lineages of the nematode, Caenorhabditis elegans. Dev Biol 56:110-156.

Taghert PH, Goodman CS (1984) Ccll detcrmination and differentiation of identified serotonin-immunoreactive neurons in the grasshopper embryo. J Neurosci 4:989-1000.

Thoenen H, Otten U (1978) Role of adrenocortical hormones in the modulation of synthesis and degradation of enzymes involved in the formation of catecholamines. In: Frontiers in neuroendocrinology, Vol 5 (Ganon WF, Martinin L, eds), pp 163-184. New York: Raven.

Thompson KJ, Siegler MVS (1989) Properties of the small dorsal unpaired median (DUM) neurons of the grasshopper. Soc Neurosci Abstr 15:1296.

Truman JW, Booker R (1986) Adult-specific neurons in the nervous system of the moth, Manduca sexta: selective chemical ablation using hydroxyurea. J Neurobiol 17:613-625.
Truman JW, Reiss S (1988) Hormonal regulation of the shape of identified motoneurons in the moth Manduca sexta. J Neurosci 8: $765-775$.

Tyrer NM, Gregory GE (1982) A guide to the neuroanatomy of locust suboesophageal and thoracic ganglia. Philos Trans R Soc Lond [Biol] 297:91-123.

Watson AHD (1986) The distribution of GABA-like immunoreactivity in the thoracic nervous system of the locust Schistocerca gregaria. Cell Tissue Res 246:331-341.

Watson AHD, Burrows M (1981) Input and output synapses on identified motoneurons of a locust revealed by the intracellular injection of horseradish peroxidase. Cell Tissue Res 215:325-332.

Weeks JC, Truman JW (1985) Independent steroid control of the fates of motoneurons and their muscles during insect metamorphosis. J Neurosci 5:2290-2300.

Witten JL, Truman JW (1989) The distribution of GABAergic lineages in insects. Soc Neurosci Abstr 15:365. 